\title{
Pharmacological Neuroenhancement Among German University Students: Identification of Potential Risk Groups and its Relation to Psychological, Psychosocial, and Health Behavioral Factors
}

\section{Sebastian Heller}

Institute of Occupational, Social and Environmental Medicine, University Medical Center of the University of Mainz

\section{Ana Nanette Tibubos}

Diagnostics in Healthcare and E-Health, University of Trier

\section{Thilo Alexander Hoff}

Institute of Occupational, Social and Environmental Medicine, University Medical Center of the University of Mainz

\section{Antonia Maria Werner}

Department of Psychosomatic Medicine and Psychotherapy, University Medical Center of the University of Mainz

Jennifer L. Reichel

Institute of Occupational, Social and Environmental Medicine, University Medical Center of the University of Mainz

\section{Lina Marie Mülder}

Department of Work, Organizational, and Business Psychology, Institute for Psychology, Johannes Gutenberg University Mainz

\section{Markus Schäfer}

Department of Communication, Johannes Gutenberg University Mainz

\section{Daniel Pfirrmann}

Institute of Sport Science, Department Sport Medicine, Rehabilitation and Disease Prevention, Johannes Gutenberg University Mainz

\section{Birgit Stark}

Department of Communication, Johannes Gutenberg University Mainz

\section{Thomas Rigotti}

Department of Work, Organizational, and Business Psychology, Institute for Psychology, Johannes Gutenberg University Mainz

\section{Perikles Simon}


Institute of Sport Science, Department Sport Medicine, Rehabilitation and Disease Prevention, Johannes Gutenberg University Mainz

\section{Manfred E. Beutel}

Department of Psychosomatic Medicine and Psychotherapy, University Medical Center of the University of Mainz

\section{Stephan Letzel}

Institute of Occupational, Social and Environmental Medicine, University Medical Center of the University of Mainz

\section{Pavel Dietz ( $\square$ pdietz@uni-mainz.de)}

Institute of Occupational, Social and Environmental Medicine, University Medical Center of the University of Mainz

\section{Research Article}

Keywords: neuroenhancement, students, epidemiology, health behavior, prevention, substance use Posted Date: June 22nd, 2021

DOl: https://doi.org/10.21203/rs.3.rs-635721/v1

License: (c) (1) This work is licensed under a Creative Commons Attribution 4.0 International License. Read Full License 


\section{Abstract}

Aiming to develop and implement intervention strategies targeting pharmacological neuroenhancement (PN) among university students more specifically, we i) assessed the prevalence of PN among German university students, ii) identified potential sociodemographic and study-related risk groups, and iii), investigated sociodemographic, psychological, study-related psychosocial, general psychosocial and health behavior related factors predicting the 12-month prevalence of PN. Therefore, a cross-sectional online survey was administered to all students of the University of Mainz, Germany. A binary logistic regression with stepwise inclusion of the five variable groups was performed to predict $\mathrm{PN}$.

A total of $N=4,351$ students participated in the survey of which $N=3,984$ answered the question with regard to PN. Of these, $10.4 \%$ had used one substance for PN at least once in the past 12 months. The regression revealed 13 variables that were significantly related to the 12-month prevalence of PN.

Specifically, the group of health behavior variables had the strongest influence on the explained variance of PN. Therefore, an approach to the prevention of PN should be multifactorial so that it addresses social conditions, as well as education on substance use and healthy behaviors in terms of nonpharmacological strategies as alternatives of PN.

\section{Introduction}

The term "pharmacological neuroenhancement" (PN), also called "pharmacological cognitive enhancement", is generally defined as the use of illicit or prescription drugs by healthy individuals for cognitive-enhancing purposes ${ }^{1-3}$ such as enhancing alertness, attention, concentration, memory and also mood $^{4,5}$. According to this definition, the so called soft neuroenhancers (e.g. energy drinks, caffeine tablets, ginkgo biloba) are not included. There are many inconsistencies and differences in the definition of this issue ${ }^{6,7}$ but a full discussion of these would go beyond the scope of this research.

In the past decade, a considerable number of studies demonstrated that PN was not uncommon in western populations. For example, a study among 102,000 adults in the United States (US) reported a 12month prevalence of $2.1 \%$ for the use of prescription stimulants in the general population, and of $6.4 \%$ among participants in the age between 18 and 29 years. Mostly reported reasons (78.2\%) for the use were improving alertness, concentration or help to study ${ }^{8}$. Furthermore, the global drug survey from 2017 , a large cross-sectional study performed in 15 countries including 29,758 participants, reported a 12month prevalence of $6.6 \%$ for the use of prescription stimulants for cognitive enhancement, with large differences in the prevalence rates between countries ${ }^{9}$. Another study from Europe reported a lifetime prevalence for $\mathrm{PN}$ of $4.0 \%$ among 10,171 participants from the general population of Switzerland ${ }^{10}$. Furthermore, other studies assessed the prevalence of PN in specific populations and occupations, such as Franke et al. ${ }^{5}$ or Dietz et al. ${ }^{4}$, reporting a lifetime prevalence for PN of $8.9 \%$ among German-speaking surgeons, and of $19 \%$ among German-speaking economists. 
A very well examined group with an increased risk for $\mathrm{PN}$ is the collective of university students. For example, a large study comparing the non-medical use of prescription stimulants between US college students and respondents of the same age not enrolled in college $(N=15,454)$, showed that college students used prescription stimulants more often (OR 1.28, 95\% $\mathrm{Cl} 1.05,1.56)$ compared to non-students of the same age group ${ }^{11}$. Moreover, within a comprehensive review and meta-analysis, Benson et al. ${ }^{12}$ reported 12-month prevalences for the use of prescription stimulants between $5 \%$ and $35 \%$ among college students in the US, demonstrating large heterogeneity in the range of these prevalence rates. Studies among university students in Western Europe obtained results in a similar range. For example, lifetime prevalences for PN of $7.8 \%$ among 6,275 Swiss students $^{13}, 3.2 \%$ among Norwegian students ${ }^{14}$, and $19.2 \%$ in a sample of students from the United Kingdom ${ }^{15}$ were reported. The same tendencies appear among German university students, as lifetime prevalences of $4.6 \%{ }^{16}$, and 12 -month prevalence estimates between $11.9 \%{ }^{17}$ and $20 \%{ }^{18}$ were reported.

From a public health point of view, the above-mentioned figures for the use of PN, especially in university students, are alarming, because PN appears to be associated with physiological and psychological side effects, may increase mortality, and can lead to addiction ${ }^{19-24}$. Understanding the conditions and factors predicting PN, especially among the severely affected collective of university students, contributes to evidence-based planning of PN-prevention strategies, because effective programs have to target factors related to PN. Therefore, potential correlates (factors that are associated) or determinants (factors with a causal relationship) of PN necessarily have to be investigated ${ }^{25}$. In this context, some research already investigated potential variables being related to PN such as sociodemographic aspects ${ }^{17,18}$, psychological factors such as stress ${ }^{26-29}$, as well as different demands and resources ${ }^{30-33}$. Furthermore, study-related psychosocial factors such as perceived academic benefits ${ }^{34-38}$, general psychosocial factors ${ }^{39}$, as well as health behavior ${ }^{17,40}$ have also been associated with PN.

Among this body of research, studies in university students examining the role of explanatory variables in an adequate sample size are rare. Furthermore, to the best of our knowledge we are not aware of any study investigating the relation between PN and sociodemographic factors, psychological factors, studyrelated and general psychosocial factors, as well as health behavior related factors in one model. In addition, Faraone et al. ${ }^{7}$ summed up that, among other aspects, because of limited data availability, and variations in describing the use of $\mathrm{PN}$, more research would be needed to identify potential risk groups of PN use, and to develop effective prevention and treatment interventions.

To conclude, empirical studies addressing PN among university students are heterogenous regarding their methodology and results ${ }^{13-18,41}$. Moreover, there is a considerable lack of knowledge with regard to potential factors that might predict PN as well as to the identification of potential study-related risk groups. Therefore, within the present study, we addressed these issues and i) assessed the prevalence of PN among German university students aiming to ii) identify potential sociodemographic and studyrelated risk groups, especially with regard to age, gender, field of study, semester, aspired degree, and iii) investigate factors related to PN by putting sociodemographic factors, psychological factors, study- 
related and general psychosocial factors, as well as health behavior related factors in one stepwise regression model. This may enable us to identify more general factors as well as specific variables that might be more or less strongly related to PN. These results may be used to iv) develop and implement intervention strategies targeting PN among university students more specifically.

\section{Methods}

\section{Study design and survey procedure}

A cross-sectional online health survey was administered to all students of the University of Mainz, Germany $(31,213)$ in summer term (June and July) 2019 as part of an ongoing project on health promotion among students ("Healthy Campus Mainz"). Students were invited to participate through the university's central mailing list. Reminder emails were sent four times. In an introduction at the beginning of the online questionnaire, the background and purpose of the study were shortly explained, followed by a statement that participation would be anonymous and voluntary. Informed consent was obtained written at the beginning of the survey. A total number of $N=4,351$ students participated in the survey, demonstrating a response rate of $13.9 \%$ of the university's total student population at that time. Approval to perform the study was given by the ethical committee of the Medical Association of RhinelandPalatinate (application-number: 2019-14336). Participation was voluntarily and informed consent was obtained in advance to participation. The study was performed in accordance with the Code of Ethics of

the World Medical Association (Declaration of Helsinki) for experiments involving humans and the Ethical Principles and Guidelines for the Protection of Human Subjects of Research by the American Psychological Association (APA). Further information on the study design and the survey is provided by Reichel et al. ${ }^{42}$.

\section{Measures}

The online survey covered a wide range of health-related topics containing approximately 270 items. Established and validated instruments were used whenever feasible and self-developed scales were used as little as possible. A whole list of all surveyed topics and items is given by Reichel et al. ${ }^{42}$. To predict PN for the present paper, 55 independent variables with regard to the research questions were selected and classified in 5 different groups (according to the factor groups of current research, as described in the introduction): sociodemographic variables (14 variables, e.g. gender, age, semester, field of study), psychological variables (6 variables, e.g. depressive symptoms, emotional exhaustion), study-related psychosocial variables (17 variables, e.g. social support by fellow students, self-efficacy expectance), general psychosocial variables (5 variables e.g. self-criticism, impulsiveness), and health behavior related variables (13 variables e.g. alcohol use, healthy diet, physical activity). A list of the specific variables, scales, and items used for the present paper as well as the respective references is given in table 1 . 
The prevalence of PN was assessed according to Dietz et al. ${ }^{4}$. The translated question regarding PN was: "Have you ever used the following substance/-s without medical necessity, for the purpose of enhancing your cognitive performance or to better handle your studies (not for reasons of enjoyment)?". The following illicit or prescription drugs could be selected via multiple choice, and each with the scale 'never', 'within the last 30 days', 'within the last 12 months', or 'more than 12 months ago': methylphenidate (e.g. Ritalin $\AA$ ), amphetamine preparation (e.g. Adderall $\left.{ }^{\circledR}\right)$, atomoxetine (e.g. Strattera ${ }^{\circledR}$ ), modafinil (e.g. Provigil $($ ), ecstasy, ephedrine, cocaine, illicit amphetamines (e.g. Speed), crystal meth, cannabis, and 'other substances'.

Table 1

List of independent variables differentiated in the five category groups. 'Count' means the count of variables if 2 or more variables of the same scale are listed together. 


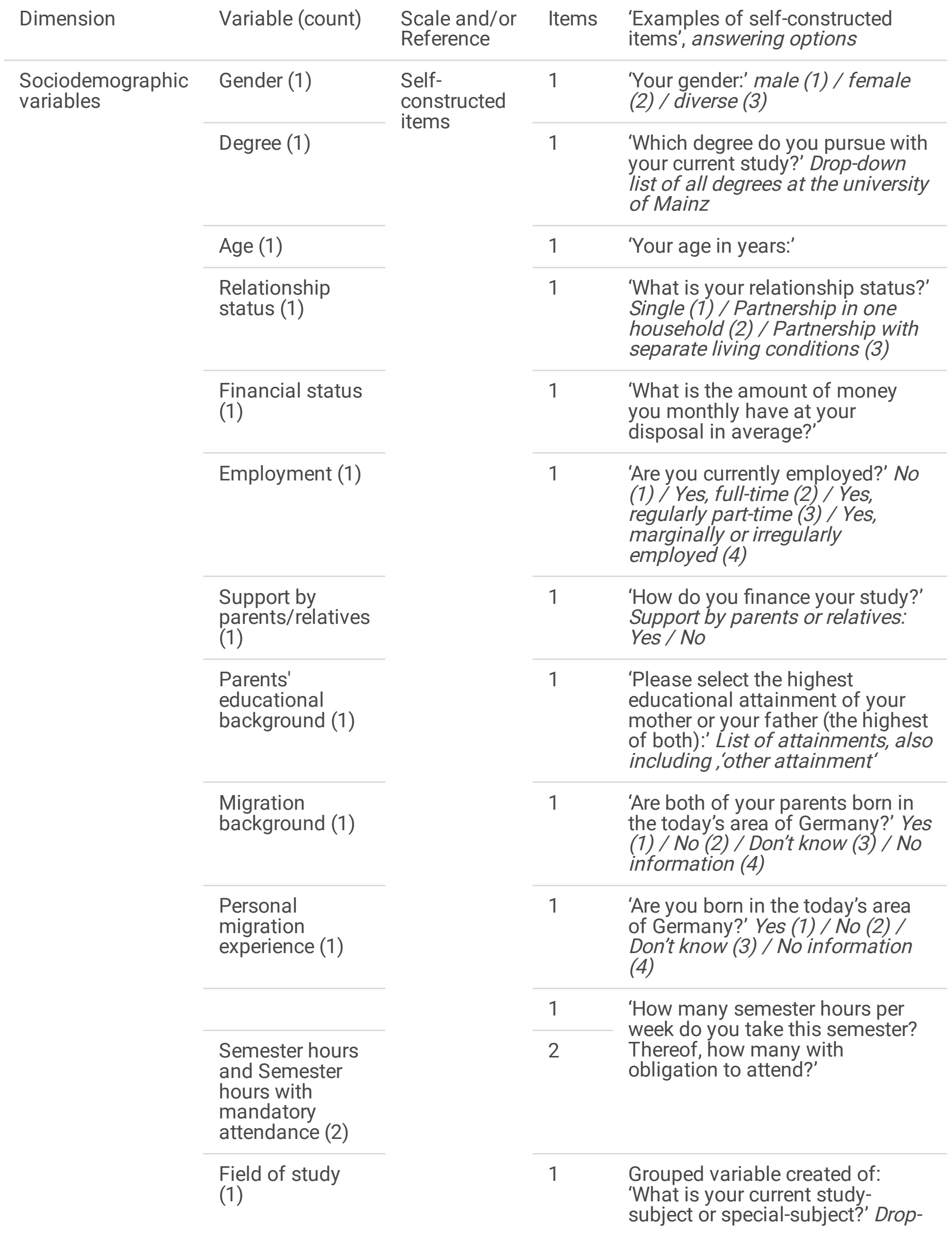


First year

(Semester/Study

progress) (1)
1 'What is the number of your current university semester?'
Psychological variables

\begin{tabular}{lll}
$\begin{array}{l}\text { Somatic } \\
\text { symptoms (1) }\end{array}$ & SSS-8 43 & 8 \\
\hline $\begin{array}{l}\text { Depressive } \\
\text { symptoms (1) }\end{array}$ & PHQ-9 44 & 9 \\
\hline $\begin{array}{l}\text { Symptoms of } \\
\text { general anxiety } \\
(1)\end{array}$ & GAD-2 $^{45}$ & 2 \\
\hline $\begin{array}{l}\text { Loneliness (1) } \\
\text { UCLA }\end{array}$ & 35 \\
\hline $\begin{array}{l}\text { Emotional } \\
\text { Exhaustion (1) }\end{array}$ & MBI-SS $^{46}$ & 5 \\
\hline $\begin{array}{l}\text { Social Anxiety } \\
(1)\end{array}$ & Mini-SPIN 47 & 3 \\
\hline
\end{tabular}

Study-related psychosocial variables

$\begin{array}{lll}\text { Presenteeism (1) } & \text { Töpritz et al. } & 1 \\ 48\end{array}$ $\begin{array}{lll}\text { Absenteeism (1) } & \text { Töpritz et al. } & 1 \\ & 48\end{array}$

Planning Dettmers \& 8

competence and Clauß 49

Competence for self-motivation

(2)

\begin{tabular}{lll}
$\begin{array}{l}\text { Excessive } \\
\text { demand } \\
\text { (qualitative) (1) }\end{array}$ & BARI-S ${ }^{50}$ & 2 \\
\hline Competition (1) & Fend $^{51}$ & 4 \\
\hline $\begin{array}{l}\text { Cognitive } \\
\text { irritation (1) }\end{array}$ & $\begin{array}{l}\text { Mohr et al. } \\
52\end{array}$ & \\
\hline $\begin{array}{l}\text { Self-efficacy } \\
\text { expectancy (1) }\end{array}$ & $\begin{array}{l}\text { Self-Efficacy } \\
\text { Scale; } \\
\text { Adapted } \\
\text { from Rigotti } \\
\text { et al. }\end{array}$ & 6 \\
\hline $\begin{array}{l}\text { Procrastination } \\
(1)\end{array}$ & $\begin{array}{l}\text { GPS-K } \\
\text { 54 }\end{array}$ & 9 \\
\hline Self- & Krause et al. & 4
\end{tabular}

Page 8/32 
endangering $\quad 55$

behavior (1)

$\begin{array}{lll}\begin{array}{l}\text { Performance } \\ \text { pressure (1) }\end{array} & \text { Fend }^{51} & 5\end{array}$

Self-perceived Self- 1

Employability constructed

(1)

Autonomy (1) BARI-S $50 \quad 6$

Coping via use In style 4

of:

of Daniels et

configuration

al. ${ }^{56}$

options and

social support

(2)

Social support $\quad$ SALSA
of:

fellow students

and

lecturers (2)

General

psychosocial variables $\begin{array}{ll}\text { Self-criticism (1) } \quad \begin{array}{l}\text { DEQ-SC4 } \\ \text { Tibubos et }\end{array} & ; 4\end{array}$

al. 59
3

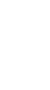

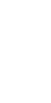




\begin{tabular}{|c|c|c|}
\hline $\begin{array}{l}\text { Physical activity } \\
\text { (MET-min/week) } \\
\text { and Sedentary } \\
\text { Behavior (2) }\end{array}$ & $\begin{array}{l}\text { IPAQ short } \\
\text { version } 63\end{array}$ & 7 \\
\hline Alcohol use (1) & $\begin{array}{l}\text { AUDIT-C } \\
\text { (Cut-Off: } 4) \\
64\end{array}$ & 3 \\
\hline $\begin{array}{l}\text { Smoking } \\
\text { cigarettes (1) }\end{array}$ & $\begin{array}{l}\text { Töpritz et al. } \\
48\end{array}$ & 1 \\
\hline $\begin{array}{l}\text { Coffee, Energy } \\
\text { drinks, Caffeine } \\
\text { tablets, Cola, } \\
\text { Ginkgo biloba } \\
\text { (5) }\end{array}$ & Dietz et al. ${ }^{4}$ & 1 \\
\hline $\begin{array}{l}\text { Social media } \\
\text { use (1) }\end{array}$ & $\begin{array}{l}\text { Adapted } \\
\text { from Stark et } \\
\text { al. }{ }^{65}\end{array}$ & 6 \\
\hline $\begin{array}{l}\text { Fruit and } \\
\text { Vegetable } \\
\text { Consumption (2) }\end{array}$ & $\begin{array}{l}\text { European } \\
\text { Commission, } \\
2013^{66} \text {; Fehr } \\
\text { et al. }{ }^{67}\end{array}$ & 4 \\
\hline
\end{tabular}

\section{Data Analysis}

Descriptive statistics are presented as means with standard deviations (SD) for continuous scaled variables and as numbers and percentages for non-continuous scaled variables. To analyze prevalence differences between sociodemographic and study-related groups, contingence-analyses of categorial variables were performed by means of Pearson chi-square $\left(\chi^{2}\right)$ tests. Therefore, the continuous variable age was dichotomized by median split. Results on the prevalence of PN are given as percentages, numbers, and p-values.

In order to enable the investigation of potential changes in the prevalence of PN in future studies, the 12month prevalence instead of the lifetime prevalence was used for all further analysis (dichotomous: 'yes' / 'no').

Pretests, using Spearman correlation for continuous (supplemental table 1) and Pearsons chi-square test for categorial variables (supplemental table 2), were performed for each of the 55 independent variables. Only variables that showed a significant association with PN in the pretest $(p \leq 0.001)$ were included into the regression analysis. A binary logistic regression with stepwise inclusion of the 5 variable groups was performed to predict PN. Multicollinearity was checked with help of a collinearity matrix and the variance inflation factor (VIF). Furthermore, an appropriate sample size of the regression model was determined by the criterion of 50 events per variable +100 . Using simulations, Bujang et al. ${ }^{68}$ revealed that this formula 
is valid to determine sample size of observational studies, independently of an observed effect size. Accordingly, for 55 variables, a minimum sample size of $n=2,850$ would be needed. Statistical analysis was performed using IBM SPSS Version 23 V5.

\section{Results}

A total of $N=3,984$ participants answered the question with regard to $P N$ and were included in the analyses. Mean age of the sample was 23.8 years $(S D=4.3$ years) and $71.3 \%(n=2,842)$ of the participants were female. With regard to study-related characteristics, $16.3 \%(n=650)$ of the participants were first-year students, $52.4 \%(n=2086)$ were studying for a bachelor's degree, $21.2 \%(n=844)$ for a master's degree, $22.0 \%(n=876)$ were aiming for a German state examination (e.g., law and medical students and students of teaching professions), and 3.5\% $(n=139)$ were PhD students. All sociodemographic and study-related characteristics of the participants are presented in table 2.

Table 2

Characteristics of the study sample. SD: standard deviation; STEM: science, technology, engineering, and mathematics. 


\begin{tabular}{|ll|}
\hline Variable & Value \\
\hline All, $n$ & 3,984 \\
\hline Gender, $n$ (\%) & \\
\hline Female & $2,842(71.3)$ \\
\hline Male & $1,110(27.9)$ \\
\hline Diverse & $32(0.8)$ \\
\hline Age, range (mean \pm SD) & $16-73(23.8 \pm 4.3)$ \\
\hline Semester, range (mean \pm SD) & $1-45(7.2 \pm 4.8)$ \\
\hline First year, $n$ (\%) & \\
\hline No & $3228(81.0 \%)$ \\
\hline Yes & $650(16.3 \%)$ \\
\hline Field of study, $n$ (\%) & \\
\hline STEM & $720(18.1)$ \\
\hline Social sciences, media or sport & $717(18.0)$ \\
\hline Philosophy, humanities or cultural sciences & $803(20.2)$ \\
\hline Medicine & $528(13.3)$ \\
\hline Law or economics & $512(12.9)$ \\
\hline Aspiring teachers & $614(15.4)$ \\
\hline Degree, $n$ (\%) & $396(1,3)$ \\
\hline Bachelor & $139(3.5)$ \\
\hline Master & \\
\hline State examination & \\
\hline Doctorate & $(52.4)$ \\
\hline Other & \\
\hline
\end{tabular}

\section{Prevalence of PN and identification of potential risk groups}

Among all participants, $15.1 \%(n=600)$ had used one of the listed substances for PN at least once in their life (lifetime prevalence), and 10.4\% $(n=416)$ at least once in the past 12 months (12-month prevalence). The most commonly used substance for PN was cannabis (7.2\% 12-month prevalence; table $3)$. 
Prevalences for the use of illicit or prescription drugs for pharmacological neuroenhancement among students at the University of Mainz $(n=3,984)$. Range of missing cases among drugs for pharmacological neuroenhancement $=1-2$ 


\begin{tabular}{|c|c|c|c|c|c|}
\hline \multirow{2}{*}{$\begin{array}{l}\text { Use of any surveyed } \\
\text { substance }\end{array}$} & \multirow{2}{*}{$\begin{array}{l}\text { Never } \\
\text { used }\end{array}$} & \multicolumn{4}{|c|}{ Used } \\
\hline & & $\begin{array}{l}\text { Total } \\
\text { responses }\end{array}$ & $\begin{array}{l}\text { Within the } \\
\text { last month }\end{array}$ & $\begin{array}{l}\text { Within the last } \\
12 \text { months }\end{array}$ & $\begin{array}{l}\text { More than } 12 \\
\text { months ago }\end{array}$ \\
\hline \multicolumn{6}{|l|}{$\begin{array}{l}\text { Prescription and } \\
\text { illicit drugs }\end{array}$} \\
\hline \multirow[t]{2}{*}{ Methylphenidate } & $97.1 \%$ & $2.9 \%$ & $0.7 \%$ & $0.7 \%$ & $1.6 \%$ \\
\hline & $\begin{array}{l}(n= \\
3,868)\end{array}$ & $(n=115)$ & $(n=26)$ & $(n=28)$ & $(n=61)$ \\
\hline \multirow{2}{*}{$\begin{array}{l}\text { Amphetamine } \\
\text { preparation }\end{array}$} & $99.6 \%$ & $0.4 \%$ & $0.1 \%$ & $0.1 \%$ & $0.8 \%$ \\
\hline & $\begin{array}{l}(n= \\
3,969)\end{array}$ & $(n=14)$ & $(n=4)$ & $(n=3)$ & $(n=7)$ \\
\hline \multirow[t]{2}{*}{ Atomoxetine } & $99.8 \%$ & $0.2 \%$ & $0.1 \%$ & $<0.1 \%$ & $<0.1 \%$ \\
\hline & $\begin{array}{l}(n= \\
3,976)\end{array}$ & $(n=7)$ & $(n=5)$ & $(n=1)$ & $(n=1)$ \\
\hline \multirow[t]{2}{*}{ Modafinil } & $99.5 \%$ & $0.5 \%$ & $0.2 \%$ & $0.1 \%$ & $0.1 \%$ \\
\hline & $\begin{array}{l}(n= \\
3,965)\end{array}$ & $(n=18)$ & $(n=9)$ & $(n=4)$ & $(n=5)$ \\
\hline \multirow[t]{2}{*}{ Ecstasy (MDMA) } & $98.3 \%$ & $1.7 \%$ & $0.3 \%$ & $0.6 \%$ & $0.7 \%$ \\
\hline & $\begin{array}{l}(n= \\
3,917)\end{array}$ & $(n=67)$ & $(n=13)$ & $(n=25)$ & $(n=29)$ \\
\hline \multirow[t]{2}{*}{ Ephedrine } & $99.6 \%$ & $0.4 \%$ & $0.1 \%$ & $0.2 \%$ & $0.2 \%$ \\
\hline & $\begin{array}{l}(n= \\
3,967)\end{array}$ & $(n=15)$ & $(n=2)$ & $(n=6)$ & $(n=7)$ \\
\hline \multirow[t]{2}{*}{ Cocaine } & $98.7 \%$ & $1.3 \%$ & $0.2 \%$ & $0.4 \%$ & $0.7 \%$ \\
\hline & $\begin{array}{l}(n= \\
3,931)\end{array}$ & $(n=53)$ & $(n=8)$ & $(n=17)$ & $(n=28)$ \\
\hline \multirow[t]{2}{*}{ Amphetamine } & $98.2 \%$ & $1.8 \%$ & $0.4 \%$ & $0.5 \%$ & $0.9 \%$ \\
\hline & $\begin{array}{l}(n= \\
3,914)\end{array}$ & $(n=70)$ & $(n=17)$ & $(n=19)$ & $(n=34)$ \\
\hline \multirow[t]{2}{*}{ Crystal Meth } & $99.9 \%$ & $0.1 \%$ & $<0.1 \%$ & $0.1 \%$ & $<0.1 \%$ \\
\hline & $\begin{array}{l}(n= \\
3,980)\end{array}$ & $(n=4)$ & $(n=1)$ & $(n=2)$ & $(n=1)$ \\
\hline \multirow[t]{2}{*}{ Cannabis } & $89.3 \%$ & $10.7 \%$ & $3.6 \%$ & $3.6 \%$ & $3.6 \%$ \\
\hline & $\begin{array}{l}(n= \\
3,557)\end{array}$ & $(n=426)$ & $(n=142)$ & $(n=142)$ & $(n=142)$ \\
\hline Other substances & $96.9 \%$ & $3.1 \%$ & $\begin{array}{c}1.4 \% \\
\text { Page } 14 / 32\end{array}$ & $0.9 \%$ & $0.8 \%$ \\
\hline
\end{tabular}




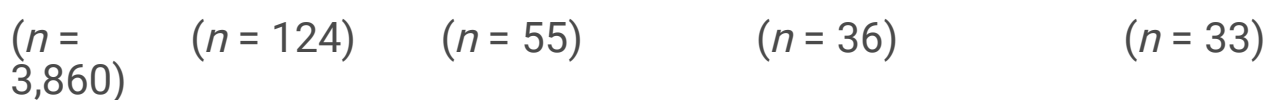

The 12-month prevalence of PN varied across sociodemographic and study-related groups. In male students, the prevalence was significantly higher $(13.2 \%)$ compared to female students $(9.3 \%, p<.001)$. First-year students showed a slightly higher 12-month prevalence (12.2\%) compared to higher semester students (9.9\%), and a significant difference was identified between bachelor (12.8\%), and master (7.7\%) students ( $p=.010$ and $p=.025$, respectively). The 12-month prevalences for all sociodemographic and study-related variables are given in table 4.

The 12-month prevalence of PN distributed for the different fields of study indicates that 'aspiring teachers' had a significantly $(p=.031)$ lower prevalence of PN $(8.1 \%)$ compared to students of 'social sciences, media and sport' (12.4\%) and 'law and economics' (12.3\%). Students of 'STEM' (science, technology, engineering, and mathematics) also had a significantly lower prevalence (9.0\%) compared to 'social sciences, media and sport' (12.4\%, table 4$)$.

Table 4

12-month prevalence of pharmacological neuroenhancement distributed for sociodemographic and study-related characteristics. 
Variable

All respondents

$(n=3,984)$

Gender

1. Female

2. Male

3. Diverse

Age $^{\#}$

1. Younger or equal 23 years

2. Older than 23 years

\section{Semester}

1. $1^{\text {st }}$ or $2^{\text {nd }}$ (first year)

2. $2^{\text {nd }}$ and above

Field of study

1. STEM

2. Social sciences, media or sport

3. Philosophy, humanities or cultural sciences

4. Medicine

5. Law or economics

6. Aspiring teachers

\section{Degree}

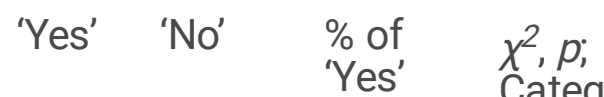

Categories with statistically significant differences

$416 \quad 3,384 \quad 10.4 \%$

$263 \quad 2,458 \quad 9.3 \% \quad \chi^{2}=21.6, p<.001 ;$

$a-b$

$146 \quad 903 \quad 13.2 \%$

$\begin{array}{lll}7 & 23 & 21.9 \%\end{array}$

$233 \quad 1,929 \quad 10.4 \% \quad \chi^{2}=12.1, p=.002$

$182 \quad 1,452 \quad 10.5 \%$

$79 \quad 554 \quad 12.2 \% \quad \chi^{2}=9.1, p=.010$

$320 \quad 2,747 \quad 9.9 \%$

$65 \quad 628 \quad 9.0 \% \quad \chi^{2}=22.6, p=.031$;

a-b; b-f; e-f

$89 \quad 598 \quad 12.4 \%$

$89 \quad 674 \quad 11.1 \%$

$51 \quad 439 \quad 9.7 \%$

$63 \quad 432 \quad 12.3 \%$

$50 \quad 537 \quad 8.1 \%$ 
1. Bachelor

2. Master

3. State Examination

4. Doctoral Student
254

63
1,734

751
$12.2 \%$

$\chi^{2}=39.3, p=.025$

a-b; a-d; b-c; c-d
$91 \quad 738 \quad 10.4 \%$

$\chi^{2}$ : Pearson Chi-square value; \#: age dichotomized by the median (23 years); STEM: science, technology, engineering, and mathematics

'Yes' reflects the summed numbers and percentage of participants answering "in the last 30 days" and "in the last 12 months" to the neuroenhancement-question.

'No' reflects the number and percentage of participants answering "never" to the neuroenhancementquestion.

'a-b'; 'a-d'; 'b-c'; 'c-d' represent significant differences $(p<.05)$ between respective categories of that variable

\section{The relation between the 12-month prevalence of PN and sociodemographic, psychological, study-related psychosocial, general psychosocial, and health-behavioral factors}

The sample size for pre-testing and binary logistic regression after the above-described protocol of dichotomization was $n=3,800$. Pre-testing (supplemental tables 1 and 2) revealed 29 variables that were significantly associated with the 12-month prevalence of PN. Due to the number of variables, case processing of the logistic regression included $n=3,584$ cases into the analysis, demonstrating an appropriate size respectively events per variable. However, the first run of the regression analysis demonstrated that the variable "degree" had to be removed from the model, because it showed $p$-values between .999 and 1 in all categories.

Subsequently, the overall model of the stepwise binary logistic regression was statistically significant, $\chi^{2}$ $(40)=490.590, p \leq .001$. Testing for multicollinearity revealed no collinearity of the chosen variables at all (with an average VIF of 1.6, the highest was 3.5 and the lowest 1.0). The stepwise regression showed changes in the explained variance of the model by stepwise inclusion of each variable group. The explained variance (Nagelkerke $R^{2}$ ) in the last step of the 5-step-model was $25.7 \%$, and it correctly classified $89.4 \%$ of cases. In the previous steps, the explained variance of the model increased from $1.0 \%$ in the 1 st to $10.0 \%$ in the 4 th step (see supplemental table 3 ). The last (5th) step of the regression revealed 13 independent variables that were significantly $(p \leq .05)$ related to the 12-month prevalence of PN (table 5): 'gender - male' (out of sociodemographic variables), 'depressive symptoms' (out of psychological variables), 'absenteeism' , 'social support by fellow students' (out of study-related psychosocial variables), 'self-criticism' (out of general psychosocial variables), and 'healthy diet', 
'moderate-vigorous physical activity', 'alcohol use', 'smoking cigarettes', 'coffee', 'caffeine tablets', 'coke', and 'ginkgo biloba' (out of health-behavioral variables). For descriptive statistics of these significant predictors, please see supplemental table 4 . The other 15 of the 28 independent variables that had been selected and showed a significant relation $(p \leq .001)$ to PN in pretests (as described earlier), were not significantly related to the 12-month prevalence of PN in the last step of the binary logistic regression model (see supplemental table 3).

Male students had a higher likelihood of PN within the last 12 months, compared to female students. 'Depressive symptoms' was positively related to the 12-month prevalence of PN. Likewise, the more the respondents regularly stayed away from their study events (i.e. absenteeism) and the more excessive they rated their demands, the higher was the likelihood of PN within the last 12 months. Negatively related variables were 'social support by fellow students' and 'self-criticism': the greater their expression, the less likely was PN within the last 12 months. Among health behavior variables, sticking to a healthy diet, extent of moderate-vigorous physical activity, risky alcohol use, currently smoking cigarettes, consumption of coffee, caffeine tablets, coke, and ginkgo biloba were positively related to the 12-month prevalence of PN.

\section{Table 5}

Significant predictors of the 12-month prevalence of pharmacological neuroenhancement in a binary logistic regression analysis with stepwise inclusion of the 5 independent variable groups: sociodemographic, psychological, study-related psychosocial, general psychosocial and health behavior related variables. 
Sociodemographic variables

Gender - male

Psychological variables

Depressive symptoms

$1.086(1.044-1.124)$

$<.001$

Study-related psychosocial variables

Absenteeism

$1.022(1.005-1.040)$

.01

Social support (fellow students)

$0.830(0.721-0.955)$

.009

General psychosocial variables

Self-criticism

$0.955(0.926-0.986)$ .004

Health behavior variables

Healthy diet

$1.264(1.117-1.431)$

$<.001$

Moderate-vigorous physical activity (min/day)

$1.001(1.000-1.002)$

.011

Alcohol use

$1.607(1.243-2.092)$

$<.001$

Smoking cigarettes

$1.468(1.349-1.597)$

$<.001$

Coffee

within the last 30 days

1.531 (1.114 - 2.106); 'never'

.009

Caffeine tablets

within the last 30 days

4.235 (2.552 - 7.027); 'never'

$<.001$

Within the last 12 months

1.763 (1.011 - 3.073); 'never'

.046

more than 12 months ago

2.117 (1.416 - 3.164); 'never'

$<.001$

Coke

within the last 30 days

1.669 (1.255 - 2.221); 'never'

within the last 12 months

2.267 (1.587 - 3.239); 'never'

$<.001$

Ginkgo biloba

within the last 30 days

2.587 (1.164 - 5.747); 'never'

.02

Observed cases: $n=3,584 ; R^{2}=0.261 ; \chi^{2}(39)=495.791 ; p<.001 ;$ please find results for all included (significant and non-significant) variables of the binary logistic regression model in supplemental table 1 


\section{Discussion}

Using a cross-sectional approach, the present study aimed to i) assess the prevalence of PN among university students, ii) identify potential risk groups for PN and iii) investigate the explanatory role of sociodemographic, psychological, study-related and general psychosocial, and health-behavioral variables on PN among a large sample of German university students, in order to iv) contribute to the development and implementation of intervention strategies targeting PN among university students more specifically.

The overall 12-month prevalence for PN was $10.4 \%$. This prevalence is approximately in the middle of the reported prevalences for university students from western European countries ${ }^{13-18}$. As stated above, these differences among reported prevalences may be caused by various methodological aspects (e.g. definition of PN, survey technique or period of reported prevalence).

With regard to the second research question, namely the identification of potential risk groups for PN in the collective of university students, male students showed a significantly higher risk for PN compared to female students. This finding is in line with previous studies ${ }^{12,69,70}$, showing that substance use appears to be more common in males than in females in different populations. With regard to study-related risk groups, first-year students and bachelor students were of increased risk for PN. This implies that PN is practiced early during studies, confirming the findings of Dietz et al. ${ }^{18}$. Furthermore, the prevalence of PN varied between different fields of studies: especially students of 'social sciences, media and sport' had a higher risk for PN compared to students from other fields of study. A possible explanation may be that the use of nutritional supplements (e.g., vitamins, minerals, herbals, caffeine or creatine) is common in the field of sports and discussed to provide a gateway to the use of illicit drugs ${ }^{71-74}$.

In view of the third research question, namely the investigation of the explanatory role of sociodemographic, psychological, study-related and general psychosocial, and health-behavioral variables, gender was the only significant sociodemographic variable in the regression model. This is in accordance with results of the contingency-analysis (second research question), that male students had a higher likelihood of PN within the last 12 months compared to female students. Among the group of psychological variables 'depressive symptoms' showed a small positive association with PN. Surprisingly, other psychological variables such as 'general anxiety', 'social anxiety' or 'loneliness' were not significantly related to $P N$ in our model, although previous studies reported associations ${ }^{69,75-77}$. In contrast to our study, these studies investigated the association of the different psychological variables and PN more isolated and not in a large model, like we did in the present study. Concerning the studyrelated and general psychosocial variables, a small protective effect of 'social support by fellow students' and 'self-criticism' for the use of PN was revealed. To the best of our knowledge, these variables were not investigated before when predicting PN. In this context, more 'social support by fellow students' also could be associated with more organized studying or less competition and therefore reduce stress and the subjective need of PN to increase academic performance ${ }^{27}$. The preventive effect of 'self-criticism' could be due to higher personal standards and perfectionism of more self-critical individuals ${ }^{78}$ and 
therefore, they might rather try to reach their academic performance goals by themselves and without external help through PN. Likewise, a potential explanation for 'absenteeism' predicting PN is that staying away from lectures increases the pressure to catch up on learning material and to successfully pass an exam, so that PN may be used to cope with these demands. In the context of these results, it is also plausible that PN is a coping strategy in a vicious cycle of depression, missing in lectures, low social support and maybe other forms of substance use or self-endangering behaviors. In general, selfendangering behaviors (e.g. presenteeism or prolonging working hours) represent maladaptive coping strategies and have previously been associated with higher quantitative demands and autonomy (in a ushaped connection) among students ${ }^{79}$.

Interestingly, the group of health behavior related variables (healthy diet, extent of moderate-vigorous physical activity, alcohol use, smoking cigarettes and using soft neuroenhancing substances) contributed the most to the explanation of PN in our model. Surprisingly, although 'healthy diet' appears as a healthprotective factor for several issues ${ }^{80}$, the present results indicate that 'healthy diet' (for definition see table 1) increases the likelihood of PN. A possible explanation could be that healthy diet is also associated with cognitive benefits ${ }^{81}$, and consequently it could be used as a co-strategy for neuroenhancement. But sticking to a healthy diet might also be biased by subjective assessment of one's own diet and therefore may be an indicator of restrictive diets or eating disorders that have been investigated to positively relate to $\mathrm{PN}^{40,82}$. The extent of moderate-vigorous physical activity showed a very small positive association with PN. This might be linked with the higher prevalence of PN in the cohort of students from the faculty of 'social sciences, media and sport'. Furthermore, PN was strongly associated with other forms of drug involvement (alcohol use, smoking cigarettes). Whereas most of the final model's odds ratios were small, for the consumption of soft neuroenhancers (coffee, caffeine tablets, coke, and ginkgo biloba), we obtained medium effects on the likelihood of PN within the past 12 months. While other forms of drug use, like drinking and smoking, may be a reason for decreased academic performance ${ }^{83}$ and reinforce the apparent necessity of $\mathrm{PN}$, these soft neuroenhancers may provide a gateway to $\mathrm{PN}^{1,74,84}$. Especially for the use of caffeine tablets, relations to PN were already stated by other studies ${ }^{17,85}$. But besides these potential dangers of shifting from legal to illicit substance use, the consumption of high dosages of caffeine is also associated with adverse health-effects ${ }^{86-89}$. However, it should be noted that this block of health behavior related variables includes other forms of substance use and since PN also represents a form of substance use, a greater explanation of variance by this step seems plausible.

Additionally, it is worth noting that our model did not support a significant influence of the amount of social media use on the past 12-month prevalence of PN, referring to previous research that recommended investigating this relationship ${ }^{6}$.

Since university students represent the executives, decision makers and also parents of tomorrow, health promotion in university students may not only be beneficial for the target group, but also benefit the general society ${ }^{90}$. In order to iv) develop health promotion and prevention programs of high quality, such programs should be evidence based. Since we revealed a higher prevalence of PN in first-year and 
bachelor students, prevention of PN should start early during studies or even at the end of school. Therefore, more research on the prevalence of PN among pupils, especially in graduation classes, would also be beneficial. Consequently, given that the present results show that PN is predicted particularly by the use of soft neuroenhancers, strategies tailored to educate on the use and effects of these substances may also help to prevent the more harmful use of drugs for the same purpose. Prevention strategies on general consumption of intoxicants, like drinking and smoking, may also decrease the risk of engaging in PN, since this study demonstrated the contributing effect of a risky alcohol consumption, or smoking cigarettes. Moreover, since some individuals seem to use PN without critical reflection of potential consequences $^{38}$, students should be educated about the limited efficacy of PN in healthy individuals ${ }^{91,92}$ and that PN is not associated with better marks or increased academic performance ${ }^{93}$. Additionally, more research should focus on the role of social support in the context of $\mathrm{PN}$, because cultivating and developing social support such as networks of communication and mutual obligation acts as a great resource ${ }^{94-96}$, not only with respect to the prevention of PN. Interventions that are targeted at the risk groups and use a multifactorial approach could lead to effective prevention of PN in future. Such a multifactorial prevention approach should therefore address social conditions, and educate on substance use as well as on healthy behaviors to increase cognitive performance - such as nutrition, physical activity and mindfulness ${ }^{81,97-99}$ - and how to adopt these behaviors as habits.

With regard to potential limitations of the present study, one could argue that whenever sensitive topics are studied, participants often react in a way that negatively affects the validity of study results (underreporting and non-responding) due to hesitating to provide compromising information about themselves ${ }^{100,101}$. Therefore, other studies used indirect survey techniques such as the randomized response technique (RRT) for the assessment of socially desirable questions such as $\mathrm{PN}^{102,103}$. Since the 12-month prevalence of PN of $10.4 \%$ in our survey is comparable to those of RRT-surveys ${ }^{17}$, it may imply that an online poll is subjectively perceived as anonymous and private and therefore provides comparable results to RRTs. In general, our online survey aimed to reach all students of Mainz University. Nevertheless, as participation was voluntary, we cannot exclude a certain selection bias in our sample. For example, health interested students and students of health-related disciplines might be more likely to participate in a health survey. Because of this potential bias, the results regarding the prevalence of PN have to be interpreted with caution. Nevertheless, a strength lies in the robust associations on individual level. It also has to be noted that our study had a cross-sectional design, and therefore, no causality of the analyzed conditions can be stated.

\section{Conclusion}

This study reveals that the 12-month prevalence of PN among German university students differs in regard to sociodemographic and study-related groups, with specific risk groups being males, first study year students, and the study fields of 'social sciences, media or sport', and 'law or economics'. Therefore, future studies should be performed with respect to the prevalence of PN in school graduation classes and prevention of PN should start early during studies or even at the end of school. This study further reveals 
that a model with groups of psychological, psychosocial and health behavior related variables is suitable to explain the 12-month prevalence of PN. In that model, specifically the group of health behavior variables has the strongest influence on the explained variance of PN. Therefore, an approach to the prevention of PN should be multifactorial so that it addresses social conditions, as well as education on substance use and healthy behaviors to increase cognitive performance and cope with stress. Students should be aware of and be able to habitually implement non-pharmacological coping-strategies ${ }^{104}$ that can help to increase cognitive performance and mood such as physical activity ${ }^{105}$, nutrition, and relaxing or mindfulness techniques.

\section{Declarations}

\section{Data Availability}

The datasets generated and analyzed during the current study are stored on the server of the University Medical Center of the University of Mainz (European server) and are available from the corresponding author on reasonable request.

\section{Author Contribution Statement}

Conceptualization:

SH, AMW, ANT, TAH, JLR, LMM, MS, DP, BS, TR, PS, MEB, SL, PD

Data curation:

SH, AMW, ANT, JLR, TR, PD

Formal analysis:

SH, ANT, AMW, PD

Funding acquisition:

SL

Investigation:

SH, ANT, AMW, TAH, JLR, MS, TR, PD

Methodology:

SH, AMW, ANT, TAH, PD

Project administration: 
JLR, SH, SL, PD

Resources:

SH, ANT, TAH, AMW, JLR, LMM, MS, DP, BS, TR, PS, MEB, SL, PD

Software:

SH, ANT, AMW, TAH, PD

Supervision:

TR, MEB, PS, PD

Validation of manuscript content:

SH, ANT, TAH, AMW, JLR, LMM, MS, DP, BS, TR, PS, MEB, SL, PD

Writing - original draft:

SH, PD

Writing - review \& editing:

SH, ANT, TAH, AMW, JLR, LMM, MS, DP, BS, TR, PS, MEB, SL, PD

The manuscript has been read and approved by all named authors.

\section{Competing Interests Statement}

All authors declare no competing interests.

\section{Funding}

The research derived from the project Healthy Campus Mainz, which is funded by BARMER health insurance, Johannes Gutenberg University (JGU) Mainz and the University Medical Center of the JGU Mainz.

\section{References}

1. Dietz, P. et al. Associations between physical and cognitive doping - a cross-sectional study in 2.997 triathletes. PloS ONE 8, e78702; 10.1371/journal.pone.0078702 (2013).

2. Franke, A. G. \& Lieb, K. Pharmakologisches Neuroenhancement und "Hirndoping" : Chancen und Risiken. Bundesgesundheitsblatt, Gesundheitsforschung, Gesundheitsschutz 53, 853-859; 
10.1007/s00103-010-1105-0 (2010).

3. Sattler, S. Cognitive Enhancement in Germany. In Cognitive Enhancement, edited by F. Jotterand \& V. Dubljevic (Oxford University Press2016), pp. 159-180.

4. Dietz, P., Soyka, M. \& Franke, A. G. Pharmacological Neuroenhancement in the Field of EconomicsPoll Results from an Online Survey. Frontiers in Psychology 7, 520; 10.3389/fpsyg.2016.00520 (2016).

5. Franke, A. G. et al. Use of illicit and prescription drugs for cognitive or mood enhancement among surgeons. BMC Medicine 11, 102; 10.1186/1741-7015-11-102 (2013).

6. Coveney, C. \& Bjønness, J. Making sense of pharmaceutical cognitive enhancement: taking stock and looking forward. Drugs: Education, Prevention and Policy 26, 293-300; 10.1080/09687637.2019.1618025 (2019).

7. Faraone, S. V. et al. Systematic Review: Nonmedical Use of Prescription Stimulants: Risk Factors, Outcomes, and Risk Reduction Strategies. Journal of the American Academy of Child \& Adolescent Psychiatry 59, 100-112; 10.1016/j.jaac.2019.06.012 (2020).

8. Compton, W. M., Han, B., Blanco, C., Johnson, K. \& Jones, C. M. Prevalence and Correlates of Prescription Stimulant Use, Misuse, Use Disorders, and Motivations for Misuse Among Adults in the United States. The American Journal of Psychiatry 175, 741-755; 10.1176/appi.ajp.2018.17091048 (2018).

9. Maier, L. J., Ferris, J. A. \& Winstock, A. R. Pharmacological cognitive enhancement among non-ADHD individuals-A cross-sectional study in 15 countries. The International Journal on Drug Policy 58, 104-112; 10.1016/j.drugpo.2018.05.009 (2018).

10. Maier, L. J., Haug, S. \& Schaub, M. P. Prevalence of and motives for pharmacological neuroenhancement in Switzerland-results from a national Internet panel. Addiction 111, 280-295; 10.1111/add.13059 (2016).

11. Ford, J. A. \& Pomykacz, C. Non-Medical Use of Prescription Stimulants: A Comparison of College Students and their Same-Age Peers Who Do Not Attend College. Journal of Psychoactive Drugs 48, 253-260; 10.1080/02791072.2016.1213471 (2016).

12. Benson, K., Flory, K., Humphreys, K. L. \& Lee, S. S. Misuse of stimulant medication among college students: a comprehensive review and meta-analysis. Clinical Child and Family Psychology Review 18, 50-76; 10.1007/s10567-014-0177-z (2015).

13. Maier, L. J., Liechti, M. E., Herzig, F. \& Schaub, M. P. To Dope or Not to Dope: Neuroenhancement with Prescription Drugs and Drugs of Abuse among Swiss University Students. PloS ONE 8; 10.1371/journal.pone.0077967 (2013).

14. Myrseth, H., Pallesen, S., Torsheim, T. \& Erevik, E. K. Prevalence and correlates of stimulant and depressant pharmacological cognitive enhancement among Norwegian students. Nordic Studies on Alcohol and Drugs 35, 372-387; 10.1177/1455072518778493 (2018).

15. McDermott, H., Lane, H. \& Alonso, M. Working smart: the use of 'cognitive enhancers' by UK university students. Journal of Further and Higher Education, 1-14; 10.1080/0309877X.2020.1753179 (2020). 
16. Sattler, S. \& Wiegel, C. Cognitive test anxiety and cognitive enhancement: the influence of students' worries on their use of performance-enhancing drugs. Substance Use \& Misuse 48, 220-232; 10.3109/10826084.2012.751426 (2013).

17. Dietz, P. et al. Prevalence Estimates for Pharmacological Neuroenhancement in Austrian University Students: Its Relation to Health-Related Risk Attitude and the Framing Effect of Caffeine Tablets. Frontiers in Pharmacology 9, 494; 10.3389/fphar.2018.00494 (2018).

18. Dietz, P. et al. Randomized response estimates for the 12-month prevalence of cognitive-enhancing drug use in university students. Pharmacotherapy 33, 44-50; 10.1002/phar.1166 (2013).

19. Chen, L.-Y. et al. Prescriptions, nonmedical use, and emergency department visits involving prescription stimulants. The Journal of Clinical Psychiatry 77, e297-304; 10.4088/JCP.14m09291 (2016).

20. Franke, A. G., Lieb, K. \& Hildt, E. What users think about the differences between caffeine and illicit/prescription stimulants for cognitive enhancement. PloS ONE 7, e40047;

10.1371/journal.pone.0040047 (2012).

21. McCabe, S. E., Veliz, P., Wilens, T. E. \& Schulenberg, J. E. Adolescents' Prescription Stimulant Use and Adult Functional Outcomes: A National Prospective Study. Journal of the American Academy of Child and Adolescent Psychiatry 56, 226-233.e4; 10.1016/j.jaac.2016.12.008 (2017).

22. Westover, A. N. \& Halm, E. A. Do prescription stimulants increase the risk of adverse cardiovascular events?: A systematic review. BMC Cardiovascular Disorders 12, 41; 10.1186/1471-2261-12-41 (2012).

23. Weyandt, L. L. et al. Misuse of prescription stimulants among college students: a review of the literature and implications for morphological and cognitive effects on brain functioning. Experimental and Clinical Psychopharmacology 21, 385-407; 10.1037/a0034013 (2013).

24. Wilens, T. E. et al. Neuropsychological functioning in college students who misuse prescription stimulants. The American Journal on Addictions 26, 379-387; 10.1111/ajad.12551 (2017).

25. Miettinen, O. S. Important concepts in epidemiology. In Teaching Epidemiology, edited by J. Olsen, R. Saracci \& D. Trichopoulos (Oxford University Press, 2010), pp. 25-50.

26. Bagusat, C. et al. Pharmacological neuroenhancement and the ability to recover from stress - a representative cross-sectional survey among the German population. Substance Abuse Treatment, Prevention, and Policy 13, 37; 10.1186/s13011-018-0174-1 (2018).

27. Bruyn, S. de, Wouters, E., Ponnet, K. \& van Hal, G. Popping smart pills in medical school: Are competition and stress associated with the misuse of prescription stimulants among students? Substance Use \& Misuse 54, 1191-1202; 10.1080/10826084.2019.1572190 (2019).

28. Sattler, S. \& Schunck, R. Associations Between the Big Five Personality Traits and the Non-Medical Use of Prescription Drugs for Cognitive Enhancement. Frontiers in Psychology 6, 1971; 10.3389/fpsyg.2015.01971 (2016).

29. Wolff, W. \& Brand, R. Subjective stressors in school and their relation to neuroenhancement: a behavioral perspective on students' everyday life "doping". Substance Abuse Treatment, Prevention, 
and Policy 8, 23; 10.1186/1747-597X-8-23 (2013).

30. Giordano, A. L. et al. Collegiate misuse of prescription stimulants: examining differences in selfworth. Substance Use \& Misuse 50, 358-365; 10.3109/10826084.2014.980956 (2015).

31. Krøll, L. T. Students' non-medical use of pharmaceuticals to manage time in everyday life crises. Drugs: Education, Prevention and Policy 26, 339-346; 10.1080/09687637.2019.1585760 (2019).

32. Lazuras, L., Ypsilanti, A., Lamprou, E. \& Kontogiorgis, C. Pharmaceutical Cognitive Enhancement in Greek University Students: Differences Between Users and Non-Users in Social Cognitive Variables, Burnout, and Engagement. Substance Use \& Misuse 52, 950-958; 10.1080/10826084.2016.1267223 (2017).

33. Wolff, W., Brand, R., Baumgarten, F., Lösel, J. \& Ziegler, M. Modeling students' instrumental (mis-) use of substances to enhance cognitive performance: Neuroenhancement in the light of job demandsresources theory. BioPsychoSocial Medicine 8, 12; 10.1186/1751-0759-8-12 (2014).

34. Arria, A. M. et al. Perceived academic benefit is associated with nonmedical prescription stimulant use among college students. Addictive Behaviors 76, 27-33; 10.1016/j.addbeh.2017.07.013 (2018).

35. Holm, A. J., Hausman, H. \& Rhodes, M. G. Study strategies and "study drugs": investigating the relationship between college students' study behaviors and prescription stimulant misuse. Journal of American College Health : J of ACH, 1-10; 10.1080/07448481.2020.1785472 (2020).

36. Holt, L. J. \& McCarthy, M. D. Predictors of Prescription Stimulant Misuse in U.S. College Graduates. Substance Use \& Misuse 55, 644-657; 10.1080/10826084.2019.1692867 (2020).

37. Kusturica, J. et al. Neuroenhancing Substances Use, Exam Anxiety and Academic Performance in Bosnian-Herzegovinian First-Year University Students. Acta Medica Academica 48, 286-293; 10.5644/ama2006-124.269 (2019).

38. London-Nadeau, K., Chan, P. \& Wood, S. Building Conceptions of Cognitive Enhancement: University Students' Views on the Effects of Pharmacological Cognitive Enhancers. Substance Use \& Misuse 54, 908-920; 10.1080/10826084.2018.1552297 (2019).

39. Thiel, A. M., Kilwein, T. M., Young, K. P. de \& Looby, A. Differentiating motives for nonmedical prescription stimulant use by personality characteristics. Addictive Behaviors 88, 187-193; 10.1016/j.addbeh.2018.08.040 (2019).

40. Jeffers, A., Benotsch, E. G. \& Koester, S. Misuse of prescription stimulants for weight loss, psychosocial variables, and eating disordered behaviors. Appetite 65, 8-13; 10.1016/j.appet.2013.01.008 (2013).

41. Castaldi, S. et al. Use of cognitive enhancement medication among northern Italian university students. Journal of Addiction Medicine 6, 112-117; 10.1097/ADM.0b013e3182479584 (2012).

42. Reichel, J. L. et al. Challenge Accepted! A Critical Reflection on How to Perform a Health Survey Among University Students-An Example of the Healthy Campus Mainz Project. Frontiers in Public Health; 10.3389/fpubh.2021.616437 (2021, in press).

43. Gierk, B. et al. The somatic symptom scale-8 (SSS-8): a brief measure of somatic symptom burden. JAMA Internal Medicine 174, 399-407; 10.1001/jamainternmed.2013.12179 (2014). 
44. Kroenke, K., Spitzer, R. L. \& Williams, J. B. The PHQ-9: validity of a brief depression severity measure. Journal of General Internal Medicine 16, 606-613; 10.1046/j.1525-1497.2001.016009606.x (2001).

45. Döring, N., \& Bortz, J. Psychometrische Einsamkeitsforschung: Deutsche Neukonstruktion der UCLA Loneliness Scale [Psychometric research on loneliness: A new German version of the University of California at Los Angeles (UCLA) Loneliness Scale]. Diagnostica 39, 224-239 (1993).

46. Gumz, A., Erices, R., Brähler, E. \& Zenger, M. Faktorstruktur und Gütekriterien der deutschen Übersetzung des Maslach-Burnout-Inventars für Studierende von Schaufeli et al. (MBI-SS). Psychotherapie, Psychosomatik, medizinische Psychologie 63, 77-84; 10.1055/s-0032-1323695 (2013).

47. Wiltink, J. et al. Mini - social phobia inventory (mini-SPIN): psychometric properties and population based norms of the German version. BMC Psychiatry 17, 377; 10.1186/s12888-017-1545-2 (2017).

48. Töpritz, K. et al. Wie gesund sind Studierende der Technischen Universität Kaiserslautern? Ergebnisse der Befragung 06/15 (Schriftenreihe des AB Public Health: Prävention und psychosoziale Gesundheitsforschung: Nr. 01/P16, Berlin: Freie Universität Berlin., 2016).

49. Dettmers, J. \& Clauß, E. Arbeitsgestaltungskompetenzen für flexible und selbstgestaltete Arbeitsbedingungen. In Gestaltungskompetenzen für gesundes Arbeiten, edited by M. Janneck \& A. Hoppe (Springer Berlin Heidelberg, Berlin, Heidelberg, 2018), pp. 13-25.

50. Gusy, B. \& Lohmann, K. Berliner-Anforderungs Ressourcen Inventar für Studierende. In Instrumentenhandbuch zum Projekt, University Health Report, edited by B. Gusy \& K. Lohmann (Schriftenreihe des Instituts für Prävention und psychosoziale Gesundheitsforschung (Nr 01/P14), Berlin: Freie Universität Berlin, 2014), pp. 31-40.

51. Fend, H. Der Umgang mit der Schule in der Adoleszenz [Coping with school during adolescence] (Huber, Bern, 1997).

52. Mohr, G., Rigotti, T. \& Müller, A. Irritation - ein Instrument zur Erfassung psychischer Beanspruchung im Arbeitskontext. Skalen- und Itemparameter aus 15 Studien. Zeitschrift für Arbeits- und Organisationspsychologie A\&O 49, 44-48; 10.1026/0932-4089.49.1.44 (2005).

53. Rigotti, T., Schyns, B. \& Mohr, G. A Short Version of the Occupational Self-Efficacy Scale: Structural and Construct Validity Across Five Countries. Journal of Career Assessment 16, 238-255; 10.1177/1069072707305763 (2008).

54. Klingsieck, K. B. \& Fries, S. Allgemeine Prokrastination. Diagnostica 58, 182-193; 10.1026/00121924/a000060 (2012).

55. Krause, A. et al. Selbstgefährdung als Indikator für Mängel bei der Gestaltung mobil-flexibler Arbeit: Zur Entwicklung eines Erhebungsinstruments. Wirtschaftspsychologie(2015).

56. Daniels, K., Beesley, N., Cheyne, A. \& Wimalasiri, V. Coping processes linking the demands-controlsupport model, affect and risky decisions at work. Human Relations 61, 845-874; 10.1177/0018726708093543 (2008).

57. Rimann, M., \& Udris, I. Subjektive Arbeitsanalyse: Der Fragebogen SALSA. In Unternehmen arbeitspsychologisch bewerten. Ein Mehr-Ebenen-Ansatz unter besonderer Berücksichtigung von 
Mensch, Technik und Organisation, edited by O. Strohm, \& E. Ulich (vdf Hochschulverlag, Zürich, Switzerland, 1997), pp. 281-298.

58. Rudich, Z., Lerman, S. F., Gurevich, B., Weksler, N. \& Shahar, G. Patients' self-criticism is a stronger predictor of physician's evaluation of prognosis than pain diagnosis or severity in chronic pain patients. The Journal of Pain : Official Journal of the American Pain Society 9, 210-216; 10.1016/j.jpain.2007.10.013 (2008).

59. Tibubos, A. N. et al. Trait self-criticism in the general population: German normative data and psychometric properties of the Depressive Experiences Questionnaire Self-Criticism 4 (DEQ-SC4). Journal of Personality Assessment (2021, submitted).

60. Ryff, C. D. Happiness is everything, or is it? Explorations on the meaning of psychological well-being. Journal of Personality and Social Psychology 57, 1069 (1989).

61. Ryff, C. D. \& Keyes, C. L. The structure of psychological well-being revisited 69, 719-727 (1995).

62. Abler, B. \& Kessler, H. ERQ - Emotion Regulation Questionnaire - deutsche Fassung. In Elektronisches Testarchiv, edited by Leibniz-Zentrum für Psychologische Information und Dokumentation (ZPID) (ZPID, Trier, 2011).

63. Craig, C. L. et al. International physical activity questionnaire: 12-country reliability and validity. Medicine and Science in Sports and Exercise 35, 1381-1395;

10.1249/01.MSS.0000078924.61453.FB (2003).

64. Bush. The AUDIT Alcohol Consumption Questions (AUDIT-C): An Effective Brief Screening Test for Problem Drinking (1998).

65. Stark, B., Magin, M. \& Jürgens, P. Ganz meine Meinung? Informationsintermediäre und Meinungsbildung - eine Mehrmethodenstudie am Beispiel von Facebook (Landesanstalt für Medien Nordrhein-Westfalen (LfM), Düsseldorf, 2017).

66. European Commission. European Health Interview Survey (EHIS wave 2). Methodological Manual : 2013 edition (Publications Office of the European Union, Luxembourg, 2013).

67. Fehr, A., Lange, C., Fuchs, J., Neuhauser, H. \& Schmitz, R. Gesundheitsmonitoring und Gesundheitsindikatoren in Europa. Journal of Health Monitoring 2; 10.17886/RKI-GBE-2017-004.2 (2017).

68. Bujang, M. A., Sa'at, N., Sidik, T. M. I. T. A. B. \& Joo, L. C. Sample Size Guidelines for Logistic Regression from Observational Studies with Large Population: Emphasis on the Accuracy Between Statistics and Parameters Based on Real Life Clinical Data. The Malaysian Journal of Medical Sciences : MJMS 25, 122-130; 10.21315/mjms2018.25.4.12 (2018).

69. Dussault, C. L. \& Weyandt, L. L. An examination of prescription stimulant misuse and psychological variables among sorority and fraternity college populations. Journal of Attention Disorders 17, 8797; $10.1177 / 1087054711428740$ (2013).

70. Lucke, J. \& Partridge, B. Towards a Smart Population: A Public Health Framework for Cognitive Enhancement. Neuroethics 6, 419-427; 10.1007/s12152-012-9167-3 (2013). 
71. Barkoukis, V., Lazuras, L., Ourda, D. \& Tsorbatzoudis, H. Are nutritional supplements a gateway to doping use in competitive team sports? The roles of achievement goals and motivational regulations. Journal of Science and Medicine in Sport 23, 625-632; 10.1016/j.jsams.2019.12.021 (2019).

72. Dietz, P. et al. Physical and cognitive doping in university students using the unrelated question model (UQM): Assessing the influence of the probability of receiving the sensitive question on prevalence estimation. PloS ONE 13, e0197270; 10.1371/journal.pone.0197270 (2018).

73. Garthe, I. \& Maughan, R. J. Athletes and Supplements: Prevalence and Perspectives. International Journal of Sport Nutrition and Exercise Metabolism 28, 126-138; 10.1123/ijsnem.2017-0429 (2018).

74. Heller, S., Ulrich, R., Simon, P. \& Dietz, P. Refined Analysis of a Cross-Sectional Doping Survey Among Recreational Triathletes: Support for the Nutritional Supplement Gateway Hypothesis. Frontiers in Psychology 11, 561013; 10.3389/fpsyg.2020.561013 (2020).

75. Schepis, T. S., Ford, J. A., Wilens, T. E., Teter, C. J. \& McCabe, S. E. Differences in Prescription Stimulant Misuse Motives Across Adolescents and Young Adults in the United States. The Journal of Clinical Psychiatry 81; 10.4088/JCP.20m13302 (2020).

76. Teter, C. J., Falone, A. E., Cranford, J. A., Boyd, C. J. \& McCabe, S. E. Nonmedical use of prescription stimulants and depressed mood among college students: frequency and routes of administration. Journal of Substance Abuse Treatment 38, 292-298; 10.1016/j.jsat.2010.01.005 (2010).

77. Verdi, G., Weyandt, L. L. \& Zavras, B. M. Non-Medical Prescription Stimulant Use in Graduate Students: Relationship With Academic Self-Efficacy and Psychological Variables. Journal of Attention Disorders 20, 741-753; 10.1177/1087054714529816 (2016).

78. Thompson, R. \& Zuroff, D. C. The Levels of Self-Criticism Scale: comparative self-criticism and internalized self-criticism. Personality and Individual Differences 36, 419-430; 10.1016/S01918869(03)00106-5 (2004).

79. Mülder, L. M. et al. Antecedents and Moderation Effects of Maladaptive Coping Behaviors Among German University Students. Frontiers in Psychology 12; 10.3389/fpsyg.2021.645087 (2021).

80. Aune, D. et al. Fruit and vegetable intake and the risk of cardiovascular disease, total cancer and allcause mortality-a systematic review and dose-response meta-analysis of prospective studies. International Journal of Epidemiology 46, 1029-1056; 10.1093/ije/dyw319 (2017).

81. Carrillo, J. Á., Zafrilla, M. P. \& Marhuenda, J. Cognitive Function and Consumption of Fruit and Vegetable Polyphenols in a Young Population: Is There a Relationship? Foods 8; 10.3390/foods8100507 (2019).

82. Nutley, S. K., Mathews, C. A. \& Striley, C. W. Disordered eating is associated with non-medical use of prescription stimulants among college students. Drug and Alcohol Dependence 209, 107907; 10.1016/j.drugalcdep.2020.107907 (2020).

83. Arria, A. M. \& DuPont, R. L. Nonmedical prescription stimulant use among college students: why we need to do something and what we need to do. Journal of Addictive Diseases 29, 417-426; 10.1080/10550887.2010.509273 (2010). 
84. Kandel, D. B. Examining the Gateway Hypothesis: Stages and Pathways of Drug Involvement. In Stages and pathways of drug involvement. Examining the gateway hypothesis, edited by D. B. Kandel (Cambridge University Press, Cambridge, UK, New York, 2002), pp. 3-16.

85. Grant, J. E., Redden, S. A., Lust, K. \& Chamberlain, S. R. Nonmedical Use of Stimulants Is Associated With Riskier Sexual Practices and Other Forms of Impulsivity. Journal of Addiction Medicine 12, 474-480; 10.1097/ADM.0000000000000448 (2018).

86. Banerjee, P., Ali, Z., Levine, B. \& Fowler, D. R. Fatal caffeine intoxication: a series of eight cases from 1999 to 2009. Journal of Forensic Sciences 59, 865-868; 10.1111/1556-4029.12387 (2014).

87. Jackson, D. A. E. et al. Behavioral and physiologic adverse effects in adolescent and young adult emergency department patients reporting use of energy drinks and caffeine. Clinical Toxicology (Philadelphia, Pa.) 51, 557-565; 10.3109/15563650.2013.820311 (2013).

88. Silva, A. C. et al. Caffeine and suicide: a systematic review. CNS \& Neurological Disorders Drug Targets 13, 937-944; 10.2174/1871527313666140612123656 (2014).

89. Temple, J. L. et al. The Safety of Ingested Caffeine: A Comprehensive Review. Frontiers in Psychiatry 8, 80; 10.3389/fpsyt.2017.00080 (2017).

90. Okanagan Charter: An International Charter for Health Promoting Universities and Colleges. An outcome of the 2015 International Conference on Health Promoting Universitites and Colleges / VII International Congress (Kelowna, Canada, 2015).

91. Repantis, D., Schlattmann, P., Laisney, O. \& Heuser, I. Modafinil and methylphenidate for neuroenhancement in healthy individuals: A systematic review. Pharmacological Research 62, 187206; 10.1016/j.phrs.2010.04.002 (2010).

92. Ullrich, S. et al. Feeling smart: Effects of caffeine and glucose on cognition, mood and self-judgment. Physiology \& Behavior 151, 629-637; 10.1016/j.physbeh.2015.08.028 (2015).

93. Arria, A. M. et al. Do college students improve their grades by using prescription stimulants nonmedically? Addictive Behaviors 65, 245-249; 10.1016/j.addbeh.2016.07.016 (2017).

94. Chao, R. C.-L. Managing Perceived Stress Among College Students: The Roles of Social Support and Dysfunctional Coping. Journal of College Counseling 15, 5-21; 10.1002/j.2161-1882.2012.00002.x (2012).

95. Pearson, J. E. The Definition and Measurement of Social Support. Journal of Counseling \& Development 64, 390-395; 10.1002/j.1556-6676.1986.tb01144.x (1986).

96. Yasin AS, D. M. A. The relationship between social support and psychological problems among students. International Journal of Business and Social Science 1, 110-116 (2010).

97. Dresler, M. et al. Hacking the Brain: Dimensions of Cognitive Enhancement. ACS Chemical Neuroscience 10, 1137-1148; 10.1021/acschemneuro.8b00571 (2019).

98. Gill, L.-N., Renault, R., Campbell, E., Rainville, P. \& Khoury, B. Mindfulness induction and cognition: A systematic review and meta-analysis. Consciousness and Cognition 84, 102991; 10.1016/j.concog.2020.102991 (2020). 
99. Sousa Fernandes, M. S. de et al. Effects of Physical Exercise on Neuroplasticity and Brain Function: A Systematic Review in Human and Animal Studies. Neural Plasticity 2020, 8856621; $10.1155 / 2020 / 8856621$ (2020).

100. Lee, R. M. \& Renzetti, C. M. The Problems of Researching Sensitive Topics. American Behavioral Scientist 33, 510-528; 10.1177/0002764290033005002 (1990).

101. Lensvelt-Mulders, G. J. L. M., Hox, J. J., van der Heijden, P. G. M. \& Maas, C. J. M. Meta-Analysis of Randomized Response Research. Sociological Methods \& Research 33, 319-348; 10.1177/0049124104268664 (2005).

102. Campbell, A. A. Randomized response technique. Science (New York, N.Y.) 236, 1049; 10.1126/science.3576215 (1987).

103. Moshagen, M., Musch, J., Ostapczuk, M. \& Zhao, Z. Reducing socially desirable responses in epidemiologic surveys: an extension of the randomized-response technique. Epidemiology (Cambridge, Mass.) 21, 379-382; 10.1097/EDE.0b013e3181d61dbc (2010).

104. Dresler, M. et al. Non-pharmacological cognitive enhancement. Neuropharmacology 64, 529-543; 10.1016/j.neuropharm.2012.07.002 (2013).

105. Dietz, P. The Influence of Sports on Cognitive Task Performance - A Critical Overview. In Cognitive Enhancement. An Interdisciplinary Perspective, edited by E. Hildt \& A. G. Franke (Springer, Dordrecht, 2013), Vol. 1, pp. 67-72.

\section{Supplementary Files}

This is a list of supplementary files associated with this preprint. Click to download.

- SupplementalMaterialHelleretal..pdf 